\title{
A modal analysis based on reactive power compensation on 6-bus Oman electrical grid
}

\author{
Adnan Saif Al Mamari', Siti Fauziah Toha², Salmiah Ahmad ${ }^{3}$, Ali Salim Al Mamari ${ }^{4}$ \\ ${ }^{1,2,3}$ Department of Mechatronics Engnieering, International Islamic University Malaysia (IIUM), Kuala Lumpur, \\ Malaysia \\ ${ }^{4}$ Oman Electricity Transmission Company, Muscat, Oman
}

\section{Article Info}

Article history:

Received Oct 12, 2020

Revised Feb 2, 2021

Accepted Apr 25, 2021

\section{Keywords:}

Jacobian matrix

Load flow algorithm

Newton-Raphson

Reactive power compensation

Voltage stability

\begin{abstract}
This paper covers the modal analysis application (MATLAB 2019a) for improving the voltage profiles by optimum positioning of the capacitor banks for 6-bus Oman Electrical System because the Oman electricity Transmission Company (OETC) is suffering of drop voltage in these 6 buses especially during summer season as a peak period. The Newton-Raphson (N-R) method will help to determine the required reactive power for each load bus and as well the ideal position or point of capacitors. The process aims to maintain the Q-V relations of the electrical grid by correlating the lowest Eigen-values to related Eigen-vectors in obtained Jacobian matrix. It depends on the Eigen-values, if they are positive then the system's voltage is stable otherwise it is not stable. In a stable system, the potential voltage collapse could be anticipated by checking the participation factors for a group of minimal positive Eigen-values. In general, the critical weak bus is associated with lower Eigen-values. Electrical system collapse is attributable to the weakest bus in the network and it could be avoided by determining the weak buses and providing capacitor banks at suitable locations which will lead to improve the voltage stability margin.
\end{abstract}

This is an open access article under the CC BY-SA license.

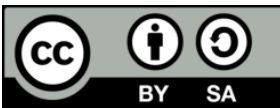

\section{Corresponding Author:}

Siti Fauziah Toha

Department of Mechatronics Engineering

International Islamic University Malaysia (IIUM)

Jalan Gombak, 53100, Selangor, Malaysia

Email: tsfauziah@iium.edu.my

\section{INTRODUCTION}

In recent years, the electrical load demands have been increased and because of the system voltage security, the power transfer between villages, towns and industrial areas have emerged for the concern [1], [2]. A lot of disturbances in electrical power due to voltage collapse and instability as it happens with the selected 6-bus Oman grid. Therefore, in order to overcome these problems, the voltage stability needs to be analyzed and studied deeply. There are some reasons which lead to voltage instability such as inadequate of reactive power, high load on transmission line, lack of voltage sources and the distances between the source and utility [3]-[6]. Generally, voltage instability is related to imbalanced reactive power. In the power system, the load bus capability relys on reactive power support which it received from the electrical system. Voltage instability leads to voltage collapse where the system unable to recover again and usually it starts with rapid reduction of voltage [4]-[7]. There are two classifications of analysis methods of voltage stability issues which are dynamic and static. Static method involves [8]; i) modal analysis/Eigen vectors and values, ii) Q-V and $\mathrm{P}-\mathrm{V}$ curves, and iii) power flow analysis. 
Flexible alternating current transmission system (FACTS) devices are widely used for solving the voltage instability. FACTS devices are considered one of the most effective solutions for reducing the power losses and improving the voltage profile in electrical grid because of their fast and flexibility of control [5][10]. In addition, they can provide high loading capacity and reducing or get rid of the blackouts. These devices can be used effectively by determining the weak bus in the electrical system where they should take a place to supply the required reactive power [11].

Optimal capacitor placement is considered one of the most effective solutions for reducing the power losses and improving the voltage profile in electrical grid [12]-[14]. By using the capacitors, the required reactive power for each load bus is supplied. There are issues in capacitors optimal placement for reducing the power losses in distribution network such as [15]; i) changeable behavior of the load buses, ii) intricacy of electrical grid, iii) different types of the loads network, iv) uncertainty in returning of the expenditure which used for capacitor placement.

In case the modal analysis of the Jacobean matrix is very close to the point of collapse [16], this will increase the ability of the operator to determine the weak bus and select the optimal placement of capacitor banks where the reactive power injection will support the system most. The information about the loads which are affecting the voltage collapse could be obtained from Eigen-vectors and their associated Eigenvalues [15]-[18]. The reduced Jacobean matrix for Newton-Raphson (N-R) can be established as per in [19].

\section{MODAL ANALYSIS TO IMPROVE VOLTAGE PROFILES}

A system is voltage steady at given operating circumstance if for each bus in the system, the bus voltage magnitude will increase as reactive energy injection at that bus is increased. In other words, a system is voltage secure if V-Q sensitivity is positive for each bus and unstable if it is negative for at least one bus. The Jacobian of N-R load flow algorithm is considered in terms of (1) and (2). Where, $\Delta \mathrm{P}$ is the incremental change in bus real power, $\Delta \mathrm{Q}$ is the incremental change in bus reactive power injection, $\Delta \delta$ is the incremental change in bus voltage angle, $\Delta \mathrm{V}$ is the incremental change in bus voltage magnitude and the sub matrices $\mathrm{J}_{1}$ to $\mathrm{J}_{4}$ are the partitioned matrices of the Jacobian Matrix $\mathrm{J}$.

$$
\begin{aligned}
& {\left[\begin{array}{l}
\Delta P \\
\Delta Q
\end{array}\right]=\left[\begin{array}{ll}
\frac{\partial P}{\partial \delta} & \frac{\partial P}{\partial V} \\
\frac{\partial Q}{\partial \delta} & \frac{\partial Q}{\partial V}
\end{array}\right]\left[\begin{array}{c}
\Delta \delta \\
\Delta|V|
\end{array}\right]} \\
& {\left[\begin{array}{l}
\Delta P \\
\Delta Q
\end{array}\right]=\left[\begin{array}{ll}
J_{1} & J_{2} \\
J_{3} & J_{4}
\end{array}\right]\left[\begin{array}{c}
\Delta \delta \\
\Delta|V|
\end{array}\right]}
\end{aligned}
$$

This conventional load flow is used for reactive power compensation studies and it also helps in voltage stability studies. The power flow equations are solved using the N-R Method. Real and reactive power will affect the voltage stability. However, at each operating point, $\mathrm{P}$ is constant and stability is evaluated by considering the incremental relation between $\mathrm{Q}$ and $\mathrm{V}$, although incremental changes in $(\mathrm{P})$ are neglected in the formulation. The expression of the incremental changes in each bus reactive power injection. $\Delta \mathrm{Q}$ is obtained based on the (1) and (2) [20].

$$
\Delta Q=\left[-J_{3} J_{1}^{-1} J_{2}+J_{4}\right] \Delta|V|
$$

It is obvious that the modal analysis by using the Jacobian matrix has more computational difficulty than of the reduced Jacobian matrix, thus the reduced Jacobian approach $\left(J_{R}\right)$ is followed here as (4) for 6-bus Oman grid [20], [21]. It represents a linear relation between the change in bus voltage $(\Delta \mathrm{V})$ and the injection of reactive power at each bus $(\Delta \mathrm{Q})$ at unchangeable active power.

$$
\Delta Q=J_{R} \Delta|V|
$$

\subsection{Modes and voltage stability}

The reduced Jacobian matrix has right and left Eigen-vectors as (4) which is resulting in participation factors that can be defined as [21], [22].

$$
J_{R}=\xi \lambda \eta
$$


where $\xi$ is the matrix of right eigen-vectors, $\eta$ is the matrix of left Eigen-vectors and $\lambda$ is the matrix of diagonal Eigen-values of matrix $J_{R}$. The smaller the Eigen-values, the more the bus's participation factor indicates the point closer to voltage instability; i) $\lambda_{\mathrm{i}}=0$, voltage collapses, ii) $\lambda_{\mathrm{i}}>0$, stable voltage-modal voltage and reactive power changes are proportional to each, and iv) $\lambda_{\mathrm{i}}<0$, unstable voltage-modal voltage and reactive power changes are in the reverse direction.

Thus, by checking the status of the eigenvalues, machine stability can be evaluated. It should be remembered that the entire individual values of a voltage stable system would be positive. If all of the eigenvalues are negative, the voltage is unstable. The reduced Jacobian matrix's zero value means that the system is on the verge of voltage instability. The smaller the magnitude of eigenvalues, the closer the voltage is unstable to the corresponding modal voltage.

Eigen value analysis is considered as one of the tools to determine voltage collapse in power system grid [11]. It has computational process of the Eigen valves for reduced Jacobian matrix which obtained from Newton-Raphson load flow solution. It gives a relative measure to voltage instability because Eigen values show the relation between the voltage and reactive power differences which will help to find out the weakest bus in the network by effective use of participation factor [16], [19], [23]. The magnitude of the Eigen-values can evaluate the instability of the electrical system, whereas the Eigen-vectors give the data for loss of the voltage stability [24], [25]. Generally, the modal analysis relies on the matrix of diagonal eigen-values of matrix $J_{R}(\lambda)$. Thus, the reduced Jacobian matrix determines the condition of the given electrical system with respect to voltage stability [22].

\subsection{Bus participations factors}

The use of right and left eigen vectors of the reduced Jacobian matrix $J_{R}$ of (5) leads to the notion of participation factors. The participation factor of bus-k to mode-i is defined as [13].

$$
P_{k i}=\xi_{k i} \eta_{k i}
$$

where $\mathrm{P}_{\mathrm{ki}}$ indicates the contribution of eigenvalues corresponding to load bus $\mathrm{i}$ to the $\mathrm{V}-\mathrm{Q}$ sensitivity at bus $\mathrm{k}$. The higher values of $\mathrm{P}_{\mathrm{ki}}$ result in larger contribution of $\lambda_{\mathrm{i}}$ in determining V-Q sensitivity at bus $\mathrm{k}$. For all the small eigenvalues, bus participation factors determine the area closer to voltage instability.

\subsection{Proposed algorithm}

The stable electrical system could move towards the instability and this situation can be determined by participation factor for minimum positive Eigen-values. The flowchart shows the steps how to reach the weakest bus is in Figure 1. The proposed algorithm consists of calculation of the required $V_{A R}$, reactive voltage and calculation of eigen-values of matrix $J_{R}$. Finally, the weakest bus in the grid is determined only after the identification of least positive Eigen-values and the determination of the corresponding participation factor, $P_{k i}$.

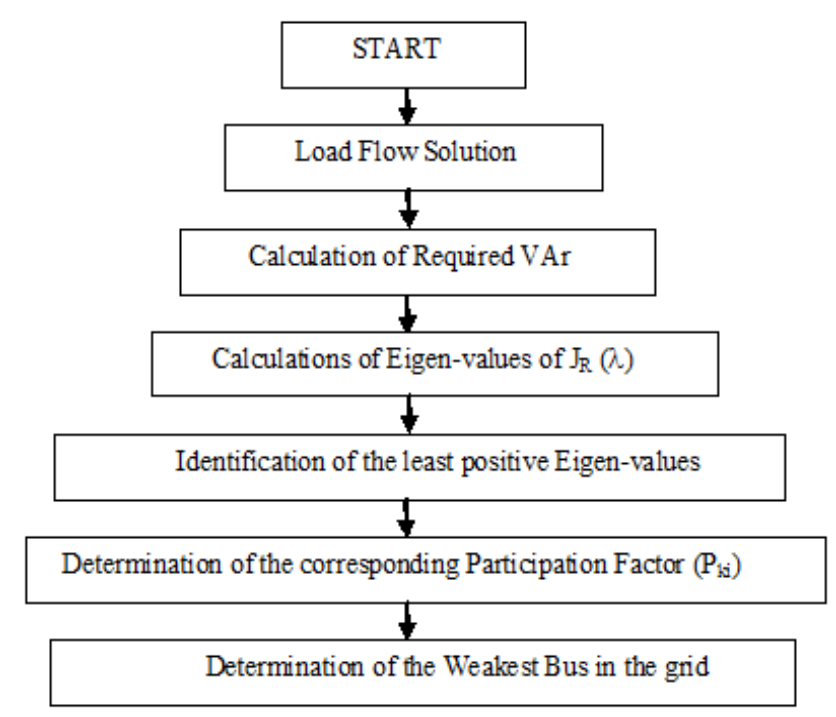

Figure 1. Flowchart of steps using to determinate the weakest bus 


\section{RESULTS AND DISCUSSION}

A computer program implementing in MATLAB2019a in order to evaluate the efficiency of the chosen Oman electrical system. In this paper, a single line diagram of 6-bus Oman electrical grid as shown in Figure 2 has been used to apply the modal analysis. The Oman 6 bus Electrical System is used to to show the practicalbility of proposed alogorithm. Bus 1 is the reference bus; bus 2 is a PV bus, while bus 4 to 6 are load buses. The line data and bus data are shown in Tables 1 and 2 respectively.

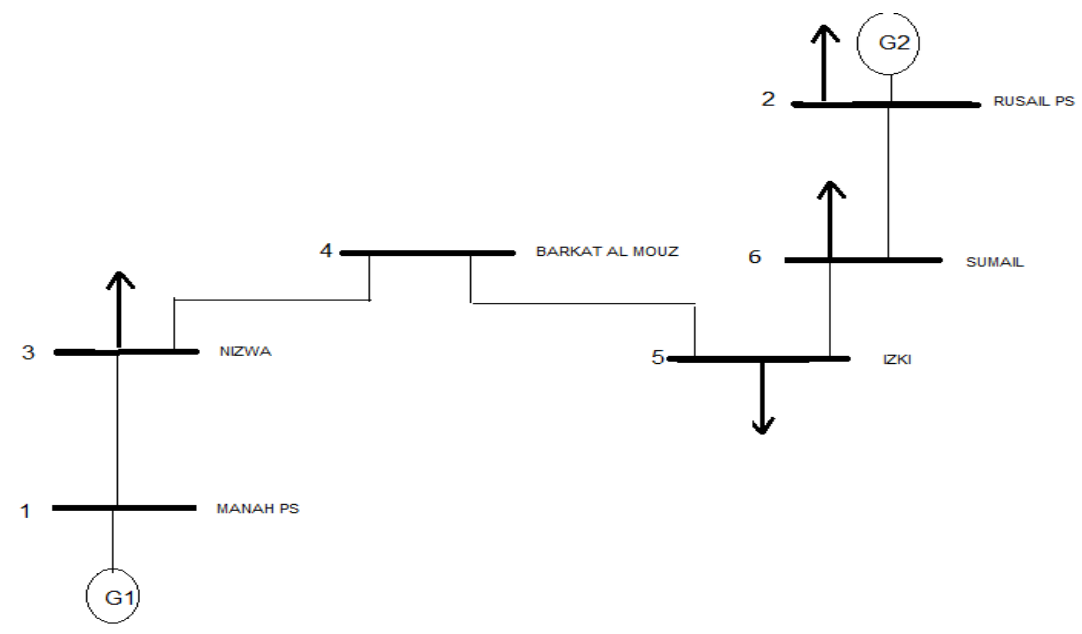

Figure 2. 6-bus Oman electrical grid

Table 1. Line data for a 6-bus Oman electrical grid

\begin{tabular}{|c|c|c|c|c|c|c|c|c|c|}
\hline \multirow[t]{2}{*}{ Line No. } & \multicolumn{2}{|c|}{ Bus Number } & \multirow[t]{2}{*}{ Length $(\mathrm{km})$} & \multicolumn{2}{|c|}{$\begin{array}{l}\text { Total Impedances } \\
\Omega / \text { Length }(\mathrm{km})\end{array}$} & \multicolumn{2}{|c|}{$\begin{array}{l}\text { Total Impedances } \\
\text { p.u/ Length }(\mathrm{km})\end{array}$} & \multirow{2}{*}{$\begin{array}{l}\text { Half line charging } \\
\text { Admittance p.u } \\
\text { B/2 }\end{array}$} & \multirow{2}{*}{$\begin{array}{l}\text { Tap } \\
\text { ratio } \\
-\end{array}$} \\
\hline & From & To & & $\mathrm{R}$ & $\mathrm{X}$ & $\mathrm{R}$ & $\mathrm{X}$ & & \\
\hline 1 & 1 & 3 & 20 & 0.4283 & 2.82100 & 0.002458 & 0.01619 & 0 & - \\
\hline 2 & 3 & 4 & 15.5 & 0.3319 & 2.18620 & 0.001905 & 0.012547 & 0 & - \\
\hline 3 & 4 & 5 & 16.5 & 0.3533 & 2.32730 & 0.002027 & 0.013357 & 0 & - \\
\hline 4 & 5 & 6 & 60.9 & 1.30417 & 8.58994 & 0.007484 & 0.049299 & 0 & - \\
\hline 5 & 6 & 2 & 34.5 & 0.738817 & 4.86622 & 0.004240 & 0.027928 & 0 & \\
\hline
\end{tabular}

Table 2. Bus data for a 6-bus Oman electrical grid

\begin{tabular}{ccccccc}
\hline Bus & \multicolumn{2}{c}{ Voltage } & \multicolumn{2}{c}{ Generation } & \multicolumn{3}{c}{ Load } \\
No. & V (p.u) & $\Theta(\mathrm{deg})$ & $\mathrm{P}(\mathrm{MW})$ & $\mathrm{Q}(\mathrm{MVAR})$ & $\mathrm{P}(\mathrm{MW})$ & $\mathrm{Q}$ (MVAR) \\
\hline 1 & 1.00 & 0 & - & - & - & - \\
2 & 1.00 & 0 & 70 & 0 & - & - \\
3 & 1.0 & - & - & - & 115 & 38 \\
4 & 1.0 & - & - & - & 0 & 0 \\
5 & 1.0 & - & - & - & 50 & 17 \\
6 & 1.0 & - & - & - & 102 & 34 \\
\hline
\end{tabular}

The load flow is performed on the 6-bus Oman electrical grid and the base-case results are obtained. Since it is required to improve the bus-voltage profile, the modal analysis-based approach is preferred. Figure 3 is additional reactive power required to maintain voltage at 1PU. The load flow solution had been implemented on 6-bus Oman electrical system in order to improve the voltage profiles and its results as shown in Table 5. Then, the Eigen-values were calculated for reduced Jacobian matrix and the modal analysis was applied. As seen in Table 3, the Eigen-values are all positive which indicates that the 6-bus Oman system is stable and the smallest value is $\lambda=19.9833$ which corresponding to bus no 6 . Therefore, the participation factor could be calculated by (6) corresponding to the lowest value as shown in the Table 3. Now, the required reactive power values to be injected are calculated (3) as per the proposed techniques and the values so determined are tabulated in Table 4.

Figure 4 shows the participation factor for least eigen values i.e., $\lambda=19.9833$. As shown in the Table 3 , column- 4 of the participation factors for $\lambda=19.9833$ is conforming to bus no 4 returned a maximum 
participation factors of 0.8310 , which indicates that bus no 4 is the weakest bus contributing to maximum voltage collapse, hence the evaluation of the participation factor could help to determine the weakest bus. After the total required reactive $\left(\mathrm{Q}_{\mathrm{T}}=120.51 \mathrm{MVAr}\right)$ is injected in bus no 4 , the magnitude of load bus voltage improves, the improvement in voltage as Table 5 and as depicted in Figure 5 shows the comparion of volage before compensation and after compensation.

Table 3. Participation factors 6-bus Oman electrical grid

\begin{tabular}{cccccc}
\hline $\begin{array}{c}\text { Load } \\
\text { Buses }\end{array}$ & $\begin{array}{c}\text { Eigen- } \\
\text { values }\end{array}$ & \multicolumn{4}{c}{$\begin{array}{c}\text { Participation factors for } \lambda=19.98 \\
\text { (for load buses 3-6) }\end{array}$} \\
\hline 3 & 465.88 & 0.4032 & -0.5912 & -0.6532 & 0.2440 \\
4 & 225.68 & -0.1573 & 0.4841 & -0.2227 & 0.8310 \\
5 & 89.28 & -0.5924 & -0.6375 & 0.3447 & 0.3508 \\
6 & 19.98 & -0.6805 & 0.0937 & -0.6364 & -0.3558 \\
\hline
\end{tabular}

Table 4. Additional VArs required to maintaining voltage at 1 p.u. (Proposed method)

\begin{tabular}{ccccc}
\hline $\begin{array}{c}\text { Load Bus No. } \\
\text { Additional VArs } \\
\text { Required p.u }\end{array}$ & 0.5783 & 0.0057 & 0.0370 & 0.5841 \\
\hline \multicolumn{5}{c}{ Total Reactive Power, $\left(\mathrm{Q}_{\mathrm{T}}\right)=120.51 \mathrm{MVAr}$} \\
\hline
\end{tabular}

Table 5. Comparison of Results before and after capacitor placement at bus 4

\begin{tabular}{|c|c|c|c|c|}
\hline \multirow{2}{*}{$\begin{array}{l}\text { Bus } \\
\text { Number }\end{array}$} & \multirow{2}{*}{$\begin{array}{l}\text { Eigen- } \\
\text { Values- } \lambda\end{array}$} & \multirow{2}{*}{$\begin{array}{l}\text { Participation } \\
\text { factor } \\
(\lambda=19.98)\end{array}$} & \multicolumn{2}{|c|}{ Magnitude of Voltages (p.u.) } \\
\hline & & & Base Case (Before) & $\mathrm{Q}_{\text {Total at bus-4 (After) }}$ \\
\hline 1 & - & - & 1.000 & 1.000 \\
\hline 2 & - & - & 1.000 & 1.000 \\
\hline 3 & 465.88 & 0.2440 & 0.989 & 1.001 \\
\hline 4 & 225.68 & 0.8310 & 0.987 & 1.008 \\
\hline 5 & 89.28 & 0.3508 & 0.986 & 1.001 \\
\hline 6 & 19.98 & -0.3558 & 0.985 & 0.998 \\
\hline \multicolumn{3}{|c|}{ Real power loss (MW) } & 1.355 & \\
\hline
\end{tabular}

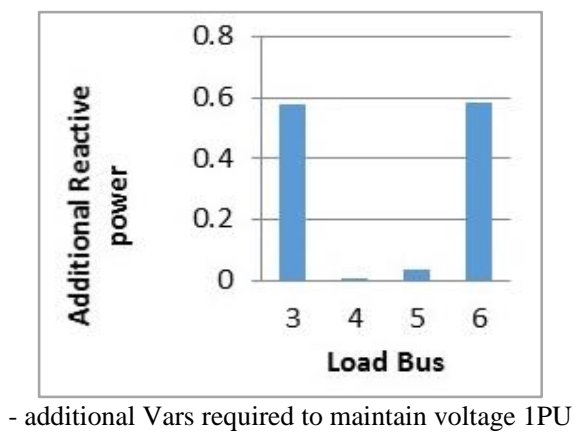

Figure 3. Additional reactive power required to Maintain voltage at 1PU

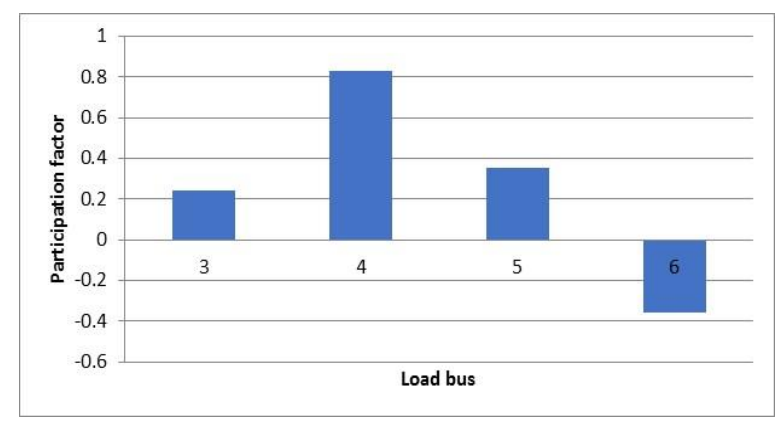

Figure 4. Participation factor for least Eigen values $\lambda=19.98$ 


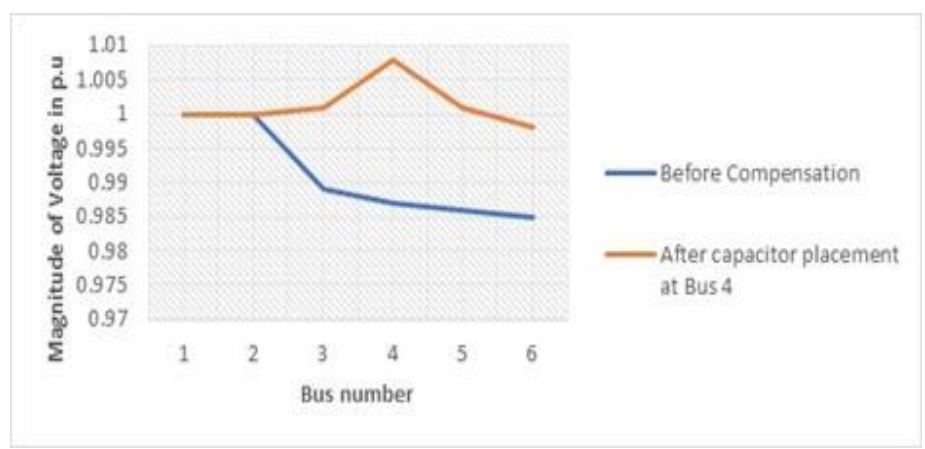

Figure 5. Voltage magnitudes before and after capacitor placement at bus 4

\section{CONCLUSION}

In this paper, the modal analysis for Eigen-values was used to determine the weakest bus or the optimal location for 6- bus Oman electrical system where the capacitor bank could be installed in order to maintain the magnitude of voltages. The weakest bus is considering as the higher contributing factor for system voltage instability and hence the voltage collapse. In addition, the condition of the system could be checked by using the Eigen-values for reduced Jacobian matrix $\mathbf{J}_{\mathrm{R}}$ with respect to voltage stability.

\section{ACKNOWLEDGMENT}

The author would like to thank financial support from the international Islamic University Malaysia under research grant IRF19-026-002: Highly Efficient Lithium-Ion Battery Recycling with Capacity-Sorted Optimization for Secondary Energy Storage System.

\section{REFERENCES}

[1] Sindhuja S, Stephen Raj A and A. Viswanathan, "Enhancement of voltage stability in an indian practical utility system under," Advances in Natural and Applied Sciences, vol. 8, no. 21, pp. 52-57, 2014.

[2] Chitra Thakur and Saurabh Sahu, "Analysis of voltage stability and transfer capability enhancement of transmission system using facts controllers," Advances in Natural and Applied Sciences, vol. 2, no. 4, pp. 2279-0535, 2013.

[3] Ahmad Fateh Mohamad Nor, Marizan Sulaiman, A. F Abdul Kadir and Rahul Omar, "Voltage instability analysis for electrical power system using voltage stabilty margin and modal analysis," Indonesian Journal of Electrical Engineering and Computer Science, vol. 3, no. 3, pp. 655-662, Sept. 2016, doi: 10.11591/ijece.v6i3.10163.

[4] Youssef A. Mobarak and Mahmoud M. Hussein, "Voltage instability and voltage collapse as influenced by cold inrush current," ICGST-ACSE Journal, vol. 12, no. 1, pp. 9-20, Jun. 2012.

[5] Niranjan, Natasha, Manisha, and Sujata, "Voltage collapse: causes and prevention," International Journal Of Engineering Research \& Technology, vol. 4, no. 2, pp. 1-4, 2016.

[6] Molekar P and Pande VN, "Voltage stability assessment and loss minimisation by power system reconfiguration," International Journal of Research \& Review, vol. 6, no. 8, pp. 468-477, 2019.

[7] Mahdi M. M. El-Arini and Raef Aboelsaud, "Optimal location of facts devices to improve power systems performance," Journal of Electrical Engineering , vol. 12, no. 3, pp. 73-80, Jan. 2012

[8] Julluri Namratha Manohar and Amarnath Jinka, "Optimization of loss minimization using FACTS in power systems," Innovative Systems Design and Engineering, vol. 3, no. 3, pp. 47-56, 2012.

[9] A. S. Siddiqui, "Optimal capacitor placement to reduce losses in distribution system," WSEAS Transactions on Power Systems, vol. 7, no. 1, pp. 12-17, 2012.

[10] S. Soleymani, B. Mozafari and M. A. Kamarposht, "Optimal capacitor placement for power loss reduction and voltage stability enhancement in distribution systems," Trakia Journal of Sciences, vol. 12, no. 4, pp. 425-430, 2014, doi: 10.15547/tjs.2014.04.013.

[11] N. Gnanasekaran, S. Chandramohan, T. D. Sudhakar and P. Sathish Kumar, "Maximum cost saving approach for optimal capacitor placement," International Journal on Electrical Engineering and Informatics, vol. 7, no. 4, pp. 665-678, 2015, doi: 10.15676/ijeei.2015.7.4.10.

[12] Yue Song, David J. Hill and Tao Liu, "State-in-mode analysis of the power flow Jacobian for static voltage stability," International Journal of Electrical Power \& Energy Systems, vol. 105, pp. 671-678, 2019, doi: 10.1016/j.ijepes.2018.09.012.

[13] Kundur P, "Power System Stability and Control," McGraw-Hill, 1994.

[14] Enemuoh F, Onuegbu J. C. and Anazia E. A., "Modal based analysis and evaluation of voltage stability of power system," International Journal of Engineering Research and Development, vol. 6, no. 12, pp. 71-79, 2013. 
[15] E. Aneke, "Enhancing the voltage stability of the nigerian 330KV 48-bus power system network using modal/eigenvalue analysis," Journal of Information Engineering and Applications, vol. 9, no. 7, pp. 31-46, 2019.

[16] D. Bică, "Steady-state analysis of voltage stability by reactive participation factor," The 6th edition of the Interdisciplinarity in Engineering International Conference "Petru Maior" University of Tîrgu Mureş, 2012.

[17] Ahmad Fateh Mohamad Nor and Marizan Sulaiman, "Voltage stability assessment of power system network using QV and PV modal analysis," Journal of Telecommunication, Electronic and Computer Engineering, vol. 8, no. 7, pp. 7-11, 2016.

[18] B. O. Anyaka, "Application of eigenvalue techniques in the analysis of dynamic stability in multi-machine power systems," Advances in Agriculture, Sciences and Engineering Research, vol. 2, no. 12, pp. 517-525, 2012.

[19] Isaac A. Samuel, James Katende and Claudius O. A. Awosope, "Prediction of voltage collapse in electrical power system networks using a new voltage stability index," International Journal of Applied Engineering Research, vol. 12, no. 2, pp. 190-199, 2017.

[20] Rohaizah bt Mohd Ghazali and Siti Nor Baizura Bt Zawawi, "Power flow analysis considering newton raphson," International Multidisciplinary Conference (IMC 2017) International, 2017.

[21] Georgios Tzounas, Ioannis Dassios and Federico Milano, "Modal participation factors of algebraic variables," IEEE Transactions on Power Systems, vol. 35, no. 1, pp. 742-750, 2020, doi: 10.1109/TPWRS.2019.2931965.

[22] Javad Sovizi, Ali Akbar Alamdari and Venkat N. Krovi, "A random matrix approach to manipulator jacobian," ASME 2013 Dynamic Systems and Control Conference, October 21-23, 2013, doi: 10.1115/DSCC2013-3950.

[23] Y. A. Mobarak, "Voltage collapse prediction for egyptian interconnected electrical grid EIEG," International Journal on Electrical Engineering and Informatics, vol. 7, no. 1, pp. 79-88, 2015, doi: 10.15676/ijeei.2015.7.1.6.

[24] Ali M. Eltamaly, Yehia Sayed and Abou-Hashema M. El-sayed, "Optimum power flow analysis by newton raphson method," International Journal of Engineering, vol. 4, no. 2, pp. 51-58, Dec. 2018.

[25] Antamil, Ardiaty Arief and Indar Chaerah Gunadin, "Allocation of reactive power compensation devices to improve voltage profile using reactive participation index," Journal of Electrical and Electronics Engineering, vol. 10, no. 4, pp. 82-90, 2015, doi: 10.9790/1676-10418290.

\section{BIOGRAPHIES OF AUTHORS}
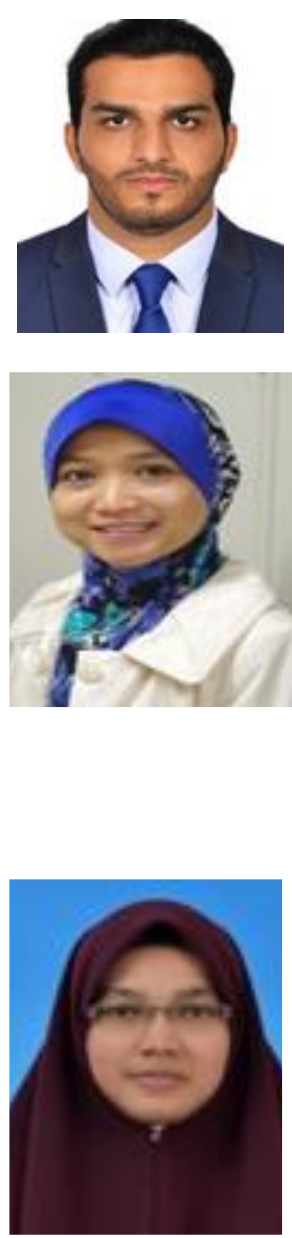

Adnan Saif Said AL Mamari received B.Eng. degree in Telecommunication and Electronics in 2012 from Middle East college and M.Eng. Degree in advanced Electrical and Electronics in 2017 from Leicester University. He is now enrolled Ph.D. degree in mechatronics engineering in international Islamic University Malaysia. His main research interest is electrical power.

Siti Fauziah Toha (B.Eng'03-M'06-PhD'10), is currently an Associate Professor at the Department of Mechatronics Engineering, International Islamic University Malaysia (IIUM). She received B. Eng (Hons) in Electrical and Electronics Engineering from University Technology Petronas and later received MSc from Universiti Sains Malaysia in electrical engineering. She was then completed her Ph. D in Automatic Control and Systems Engineering from The University of Sheffield in 2010. She was later joining the Perusahaan Otomobil Nasional Berhad (PROTON) Malaysia as control expert consultant, working with vehicle hardware-in-loop for electric vehicle development. Her current research interest is Battery Management System, Energy Optimisation for Electric Motorcycle development, Mobile Robots, Artificial Intelligence for Modelling and Control. Dr Toha is a senior member of IEEE and also a Professional Engineer in Malaysia as well as a Chartered Engineer with Engineering Council, The Institution of Engineering and Technology, United Kingdom. She is also an active member of Young Scientist Network, Academy of Sciences Malaysia (YSN-ASM).

Associate Professor Ir. Dr. Salmiah Ahmad, started her career as a Project Engineer at Toyo Engineering and Construction (M) Sdn. Bhd, after received her B.Eng in Mechatronics Engineering from International Islamic University Malaysia in 2001. Later she received her M.EngSc in Electrical Engineering from Curtin University of Technology, Australia in 2004. She was then completed her Ph.D in Automatic Control and Systems Engineering from The University of Sheffield in 2010, and currently she is an Associate Professor at the Department of Mechanical Engineering, International Islamic University Malaysia, Kuala Lumpur. In 2012, she has been appointed as a panel for Engineering Accreditation Council (EAC), to evaluate degree programme in Mechatronics and its related fielda at universities in Malaysia. She is also a Professional Engineer (P.Eng) obtained in 2016, a Chartered Engineer (CEng) and a member of The Institution of Engineering and Technology (IET), senior member of Institute of Electronic and Electrical Engineering (SMIEEE), a member of the Institution of Engineers Malaysia (MIEM), life member of MySET (Malaysian Society of Engineering and Technology) and 
PERINTIS (Muslim Scientist Organization of Malaysia). Her current research interests include; Machine Learning for Signal Processing, Electric Vehicle, Intelligent Systems and Control, Mobile Robot, Rehabilitation and Bio-signals, Instrumentation and Signal Processing.

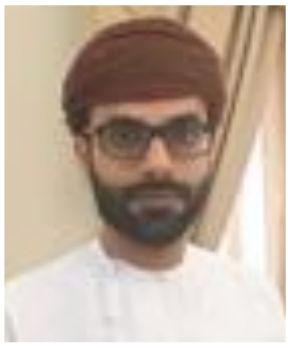

Ali Salim Almaamari is a Senior Electrical control engineer in Oman Electricity Transmission Company (OETC). He received B. Eng (Hons) in Electrical power system in 2008 from Sultan Qabbos University. Later he received MSc in Energy and power system management in 2016 from Portsmouth University, UK. He joined OETC in 2008 as Electrical control engineer. 